\title{
O (des)governo na expansão da educação superior brasileira: da inoperância do Estado à supremacia da lógica do mercado
}

\author{
Julio Cesar Godoy Bertolin*
}

\section{Resumo}

A educação superior brasileira vem passando nas últimas duas décadas por um processo de significativa expansão. A partir de meados da década de 1990 o sistema começou a apresentar um forte crescimento, especialmente por meio do credenciamento de novas instituiçóes privadas, não-universitárias. Tal processo resultou num significativo aumento nos indicadores quantitativos, tais como taxas de atendimento, quantidade de cursos de graduação e número de alunos matriculados. Entretanto, os níveis de alinhamento dessa expansão com as políticas de desenvolvimento socioeconômico e com os interesses maiores da sociedade (ou do mercado) precisam ser investigados. $\mathrm{O}$ presente artigo realiza uma revisão da literatura acerca do fenômeno da mercantilização da educação superior, apresenta e analisa aspectos e indicadores da expansão do sistema e, por fim, demonstra que os interesses privados estão sendo determinantes no desenvolvimento da educaçáo superior brasileira.

Palavras-chave: Educação Superior. Expansão do Ensino Superior. Mercantilização do Ensino.

* Doutor em Educaçáo pela Universidade Federal do Rio Grande do Sul (UFRGS). Professor da Pós-Graduação em Educação da Universidade de Passo Fundo (UPF). 


\section{Introdução}

O papel fundamental que a educação desempenha para o crescimento econômico e desenvolvimento das naçóes é uma unanimidade mundial. Há décadas estudos têm indicado que altos índices de escolaridade impactam na elevação do Produto Interno Bruto (PIB) e na melhoria de índices socioculturais. Mais recentemente, a relação empírica entre educação e crescimento econômico foi claramente estabelecida. Especificamente no âmbito dos sistemas de educação superior, tem sido possível observar que países que ampliaram suas taxas de atendimento, posteriormente, alcançaram maior crescimento econômico, elevaçáo dos salários médios e melhores resultados sociais. De acordo com a Organização das Naçôes Unidas para a Educação, a Ciência e a Cultura (UNESCO, 2005), a educaçáo superior apresentou no decorrer dos séculos ampla capacidade de transformar e induzir mudanças para o progresso das sociedades e naçóes.

Nas últimas décadas a velocidade das mudanças e a inovação se intensificaram de maneira notória, transformando o conhecimento no principal meio de produção nesse início de século XXI. Nesse contexto, as instituições de educação superior e, principalmente, as universidades desempenham um papel ainda mais fundamental para as sociedades, visto que os sistemas clássicos de produção, difusão e aplicação do saber experimentam uma mudança profunda. O preâmbulo da declaração da Conferência Mundial de Educaçáo Superior da UNESCO (1998) já havia destacado que somente a educaçáo superior e instituiçóes de pesquisa podem formar profissionais qualificados que consubstanciam a massa crítica para um país alcançar um desenvolvimento real e sustentável. O texto do comunicado final da última conferência mundial, realizada em 2009, destaca a ampliação da importância da educação superior: "Nunca na história foi tão importante investir na educação superior como força maior na construçáo de uma sociedade inclusiva e de conhecimento diversificado, além de avançar em pesquisa, inovação e criatividade" (UNESCO, 2009a, p. 1).

Assim, não há dúvida que nesse início de século XXI os sistemas de educação superior possuem, cada vez mais, um papel central no desenvolvimento social e crescimento econômico dos países.

Muito provavelmente, tal relevância da educação superior seja um dos fatores determinantes da expansão dos sistemas nacionais em desenvolvimento em escala mundial. Nas últimas décadas, os sistemas de educação superior de 
diversos países têm passado por um processo de massificação que resultou numa ampliação significativa das taxas de atendimento. Em escala global, a taxa de escolarização líquida ${ }^{1}$ subiu de $19 \%$, em 2000, para 26\%, em 2007. Segundo estimativas da UNESCO (2009b), atualmente existem aproximadamente 150 milhóes de estudantes de educação superior no mundo, o que representa um aumento de aproximadamente $53 \%$ sobre o ano de 2000 . De acordo com a diretora geral da UNESCO, Irina Bokova, a demanda global por educação superior irá se expandir até, aproximadamente, 250 milhóes de alunos em 2025.

A educação superior brasileira também está em processo de expansão. Desde o ano de 1992, último ano em que ocorreu uma redução de alunos, a quantidade de matrículas na educaçấo superior brasileira vem crescendo em média 7\% ao ano. O maior crescimento ocorreu no período 1999-2003 com média anual de aproximadamente $13 \%$. Nos últimos dez anos a quantidade de alunos matriculados mais que dobrou, saindo de 3 milhôes em 2001 para 6,4 milhôes em 2010. Entretanto, o país ainda possui baixas taxas de atendimento na comparação com países desenvolvidos e mesmo com seus vizinhos latinoamericanos. Enquanto em diversos países as taxas de escolarização bruta ${ }^{2}$, em geral, são maiores que $50 \%$, chegando a, por exemplo, $52 \%$ no Chile, $64 \%$ no Uruguai, 56\% na França, e 82\% nos Estados Unidos, no Brasil era de apenas 25\% em 2008 (WORLD BANK, 2011).

Assim, considerando a importância estratégica da educação superior para um país, cabe perguntar quais os rumos do atual processo de expansão da educação superior brasileira. Qual é o nível de alinhamento da expansão com as políticas de desenvolvimento econômico e social do país? Será que a expansão em cursos está em acordo com os interesses maiores da sociedade? E quem realmente vem definindo o rumo da expansão: o Estado ${ }^{3}$ ou o mercado ${ }^{4}$ ? Este artigo busca contribuir na busca de respostas para essas importantes questóes. Para tanto, inicialmente, realiza uma revisão da literatura acerca do processo de mercantilização e, a seguir, apresenta e analisa aspectos e indicadores do desenvolvimento do sistema que demonstram que os interesses do mercado estáo sendo determinantes no rumo da atual expansão da educação superior brasileira.

\section{O fenômeno da mercantilização da educação superior}

A educação superior é, certamente, o nível de educação que sofreu os maiores impactos das recentes tendências de privatizaçôes de políticas sociais. 
Diversos sistemas nacionais de educação superior experimentaram, no final do século XX e início do século XXI, um processo de redução do financiamento público, emergência da rede privada e ampliação de mecanismos de regulação de mercado (TEIXEIRA, 2004). De acordo com Fernanda Correia et al. (2000, p. 37),

[...] nas últimas décadas o desenvolvimento da educação superior deixou de estar vinculado à modernização liderada pelo Estado e passou a estar vinculado ao setor privado visto que os governos estão substituindo as formas tradicionais de regulação por mecanismos de mercado como instrumentos de política pública, procurando incentivar a competiçáo entre instituiçóes na procura por soluçóes mais eficazes e, certamente, mais econômicas.

Diversos estudos demonstraram que importantes organismos internacionais multilaterais, como, por exemplo, o Banco Mundial, induziram o desenvolvimento de políticas apoiadas na expansão de mercados, inclusive em escala global, que avançaram sobre a educação superior de diversos países. No documento The financing and management of higher education: a status report on worldwide reforms, de 1998, o Banco Mundial defendeu a tese de que a educação superior é antes um bem privado que público (JOHNSTONE, 1998). Ao afirmar que a educação superior responde a muitas das condiçóes identificadas por Nicholas Barr como características de um bem privado (possui condição de competitividade - oferta limitada, exclusividade - seguidamente se pode obtê-lo mediante pagamento, e recusa - não é requerido por todos), ou seja, características que não respondem às de um bem estritamente público, o Banco defendeu a tese do menor retorno social da educação superior em relação à educação fundamental.

De maneira geral, os argumentos e as justificativas para o chamado processo de mercantilização da educação superior estão relacionados com os pressupostos liberais de que a competição gerada pelo mercado levaria a uma maior produtividade e eficiência dos sistemas, com consequente melhoria na qualidade e equidade no provimento dos serviços educacionais pelas instituiçóes. Não obstante importantes autores advertirem sobre o risco da emergência da lógica de mercado na educação superior, o fato é que o contexto atual é 
de tencionamento para ampliação da lógica de mercado. Existem propostas em debate na Organização Mundial do Comércio (OMC) que se referem, inclusive, a ideia de criação de um mercado global que pretende consolidar a transnacionalizaçáo da educaçáo superior, o que, se concretizado, certamente interferirá na autonomia das nações em decidirem suas políticas educacionais nesse nível.

Segundo Julio C. G. Bertolin (2007, p. 107), a mercantilização da educação superior pode ser definida como o fenômeno onde

[...] o desenvolvimento dos fins e dos meios da educação superior, tanto no âmbito estatal como no privado, sofre uma reorientação de acordo com os princípios e a lógica do mercado e sob a qual a educação, gradativa e progressivamente, perde o status de bem público e assume a condição de serviço comercial.

Segundo o autor, no âmbito dos "meios da educação superior", as reorientaçôes para, e conforme, a lógica do mercado ocorrem através: da inserção de mecanismo de mercado na regulação dos sistemas; da introdução de modelos gerencialistas privados no governo e na gestão das instituiçóes públicas; e do incremento de instituiçóes e financiamento privados nos sistemas. Já, no âmbito dos "fins da educação superior", a reorientação para o mercado ocorre fundamentalmente por meio: da grande expansão de cursos e de instituiçóes especializadas em ensino para as demandas das empresas privadas e do mercado de maneira geral; e da emergência inédita da pesquisa e da investigação aplicada para o mercado (BERTOLIN, 2007).

Diversos autores que estudaram a evolução da relação entre o Estado e a educação superior nas últimas décadas observaram certa convergência de políticas públicas para a educação superior no sentido do fortalecimento das forças de mercado e orientação para o modelo de "Estado avaliador". Mais recentemente, parece registrar-se uma tendência para a diminuição do controle direto do Estado e conferência ao mercado de status de mecanismo de regulação. Quando um sistema de educação superior contém elementos de regulaçáo baseados na lógica do mercado, a disputa por alunos torna-se fundamental para a sustentabilidade das instituiçôes educacionais privadas ${ }^{5}$. Assim, até mesmo instituiçôes privadas sem fins lucrativos como as comunitárias e confessionais precisam adotar estratégias de concorrência características de 
empresas mercantis, como, por exemplo, publicidade e descontos, e os sistemas são induzidos a realizarem comparações entre cursos para informar a sociedade sobre as "melhores opçôes".

Por conseguinte, tem-se observado em diversos países a emergência do desenvolvimento de sistemas de acreditação, de mecanismos de avaliação e medições utilizados para a elaboração de rankings de instituiçóes e cursos (DIAS SOBRINHO, 2003) e, também, o significativo incremento da destinação de recursos das instituições de educação superior para divulgação e publicidade junto à mídia (HADDAD; GRACIANO, 2004). No Brasil, a implementação de avaliação externa de cursos de graduação em larga escala, de natureza compulsória e com abrangência nacional ocorreu, principalmente, por meio de dois diferentes métodos empregados pelo Instituto Nacional de Estudos e Pesquisas Educacionais Anísio Teixeira (Inep) a partir de 1995: o exame aplicado aos concluintes, o "provão", e a avaliação de pares, as comissões de especialistas.

Outro aspecto da mercantilização da educação superior brasileira é o aumento significativo de instituiçóes privadas não-universitária e com fins lucrativos. Os números de tal aumento demonstram o viés preponderantemente privatista da expansão da educação superior brasileira das últimas duas décadas. Em 1994, estavam credenciadas 218 instituições estatais e 633 privadas. Pouco mais de uma década depois, em 2006, eram 248 instituiçóes estatais e 2022 instituiçóes privadas, ou seja, no período ocorreu um crescimento de apenas $13 \%$ no âmbito estatal frente a um avanço de $219 \%$ no âmbito privado. Por conseguinte, também ocorreu um aumento significativo no número de cursos de graduação presenciais nas instituições privadas. No ano de 2000, eram 6,5 mil cursos privados, em 2007, 16,8 mil e, em 2012, 19,7 mil, ou seja, um crescimento em números absolutos superior a 13 mil novos cursos. No período 2000-2010, no âmbito das instituiçôes estatais federais, a criação de novos cursos de graduação presenciais foi de apenas 3 mil (INEP, 2012). Consequência inevitável da ampliação das instituições e cursos privados é o aumento da parcela de alunos matriculados na rede privada. Considerando as matrículas em cursos presenciais e a distância, entre 2000 e 2010, o crescimento das matrículas nas instituiçóes privadas foi de quase 3 milhóes de alunos, enquanto nas instituiçôes estatais foi de apenas 750 mil alunos. Em 2000, de cada 3 alunos matriculados na educação superior, um estava em instituição estatal e 2 em privada. Dez anos depois, em 2010, essa relação está em 3 alunos matriculados em instituiçôes privadas para cada aluno de instituição estatal (INEP, 2012). 
Apesar do recente esforço do governo para ampliar o acesso com recursos público e ampliação de instituições estatais federais por meio de programas como o Programa Universidade para Todos (Prouni), Programa de Apoio a Planos de Reestruturação e Expansão das Universidades Federais (Reuni) e da Universidade Aberta do Brasil (UAB), a expansão continua, se baseando, sobretudo, no âmbito das instituiçóes privadas que, em 2000, tinham 67\% das matrículas e, em 2010, estava com 74\% (Tabela 1). O Prouni, por exemplo, conhecido programa de isenção de tributo federal iniciado em 2004, tinha concessão de apenas 250 mil bolsas de estudo em instituiçóes privadas no ano de 2009.

Tabela 1 - Quantidade e porcentagem de matriculas por categoria administrativa na educaçáo superior brasileira

\begin{tabular}{|c|c|c|c|c|c|c|}
\hline & 2000 & 2002 & 2004 & 2006 & 2008 & 2010 \\
\hline Estatal & 888708 & 1086473 & 1214141 & 1247736 & 1446661 & 1643298 \\
\hline$\%$ & 33 & 31 & 29 & 26 & 24 & 26 \\
\hline Privada & 1807219 & 2434133 & 3009203 & 3636116 & 4471520 & 4736001 \\
\hline$\%$ & 67 & 69 & 71 & 74 & 76 & 74 \\
\hline Total & 2695927 & 3520606 & 4223344 & 4883852 & 5918181 & 6379299 \\
\hline
\end{tabular}

Fonte: Autor, baseado em INEP (2012).

Apesar do recente esforço do Governo Federal, a expansão em curso ainda é insuficiente. Em relação aos próprios objetivos estabelecidos pelo Plano Nacional de Educação (PNE) de 2001-2010, o Brasil ainda está muito aquém da meta da taxa de escolarização líquida de $30 \%$ estabelecida para ser alcançada no ano de 2010. A proposta do novo PNE prevê uma taxa de atendimento de escolarização bruta de $50 \%$ e de escolarização líquida de $33 \%$ para 2020 . Tais metas estabelecem um número próximo a 12 milhóes de alunos matriculados na educação superior no final da década, ou seja, o dobro do número de matrículas atualmente.

Portanto, do ponto de vista quantitativo não há dúvidas de que a expansão ainda não alcançou resultados satisfatórios. Mas e de uma perspectiva mais qualitativa, qual o desempenho da expansão da educação superior brasileira? Será que essa expansão, preponderantemente realizada por meio de instituiçóes privadas, está sendo orientada pelo Estado para atender as demandas e prioridades do país? Será que a mercantilização da educação superior brasileira vem respondendo adequadamente as demandas sociais e econômicas da nação? Segundo Boaventura de Souza Santos (2004), tal possibilidade é improvável. 
Para o autor, a importância da manutenção da educação superior como bem público está relacionada com a relevância estratégica que as instituições têm na construção de um projeto de país visto que, ao contrário das características da universidade, o mercantil possui apenas interesses de curto prazo. A seguir, serão apresentados aspectos do desenvolvimento da educação superior brasileira, com vistas a demonstrar que o interesse mercantil tem prevalecido e subjugado os interesses e demandas maiores do país.

\section{A supremacia da lógica do mercado na expansão}

Dentre as funçôes históricas da educação superior está, sem dúvida, além da pesquisa, o ensino acessível e diversificado para todos. Portanto, dentre as prioridades de um sistema de educação superior devem estar, além da produção de conhecimento, o desenvolvimento das habilidades e competências para a composição da força de trabalho qualificada e diversificada. Com objetivo de avaliação desses aspectos, organismos internacionais, tais como a UNESCO, têm monitorado indicadores relacionados ao perfil e áreas do conhecimento dos graduandos e ao acesso para todas as regiōes e grupos populacionais dos países, ou seja, a equidade no acesso. Nesse sentido, a seguir serão apresentados indicadores e realizadas análises relacionais à expansáo privada da educaçáo superior brasileira sob duas importantes perspectivas: diversidade de áreas do conhecimento dos concluintes e equidade no acesso e na conclusão na educação superior.

\section{O desequilíbrio na formação da força de trabalho}

Não há dúvidas que o crescimento econômico e o desenvolvimento social equilibrados de um país dependem da disponibilidade de força de trabalho diversificada e qualificada. Nesse sentido, é importante que a quantidade de concluintes dos cursos de graduação varie de forma equilibrada com as necessidades e demandas por profissionais dos diferentes segmentos e setores das atividades socioeconômicas do país. A título de exemplo, quando um setor constitui-se como estratégico para a autonomia científica e tecnológica de um país e, concomitantemente, ainda apresenta carência de profissionais, torna-se premente a ampliação proporcional das matrículas dos cursos de graduação e pósgraduaçáo que formam esses profissionais. Por outro lado, também é adequado que uma classe com excesso de profissionais no mundo do trabalho apresente redução de participação no conjunto de todos os alunos matriculados e concluintes. 
Nos últimos anos, no Brasil, não ocorreram mudanças substâncias na participação das diferentes áreas do conhecimento no conjunto do total de concluintes em nível de graduação e de pós-graduação stricto sensu (tabelas 2 e 3).

Tabela 2 - Porcentagem de concluintes da graduaçáo por áreas do conhecimento, 2000-2009

\begin{tabular}{l|r|r|r|r|r|r|r|r|r|c}
\hline $\begin{array}{c}\text { Área do } \\
\text { conhecimento }\end{array}$ & 2000 & 2001 & 2002 & 2003 & 2004 & 2005 & 2006 & 2007 & 2008 & 2009 \\
\hline Educação & 25,3 & 25,9 & 27,5 & 28,8 & 27,4 & 29,1 & 27,8 & 23,6 & 22,7 & 21,1 \\
\hline $\begin{array}{l}\text { Humanidades e } \\
\text { Artes }\end{array}$ & 3,3 & 3,2 & 3,4 & 3,4 & 3,5 & 3,4 & 3,5 & 3,7 & 3,7 & 3,6 \\
\hline $\begin{array}{l}\text { Ciências Sociais, } \\
\text { Negócios e Direito }\end{array}$ & 39,8 & 39,7 & 38,3 & 37,4 & 38,1 & 38,0 & 38,7 & 40,6 & 39,8 & 41,0 \\
\hline $\begin{array}{l}\text { Ciências, } \\
\text { Matemática e } \\
\text { Computação }\end{array}$ & 8,4 & 8,2 & 7,9 & 7,7 & 7,6 & 7,8 & 7,9 & 8,1 & 7,8 & 7,7 \\
\hline $\begin{array}{l}\text { Engenharia, } \\
\text { Produção e } \\
\text { Construçáo }\end{array}$ & 7,0 & 6,9 & 6,4 & 6,0 & 5,8 & 5,3 & 5,1 & 5,6 & 6,2 & 5,9 \\
\hline $\begin{array}{l}\text { Agricultura e } \\
\text { Veterinária }\end{array}$ & 2,1 & 2,1 & 2,0 & 1,9 & 1,9 & 1,6 & 1,7 & 1,8 & 2,0 & 2,0 \\
\hline $\begin{array}{l}\text { Saúde e Bem- Estar } \\
\text { Social }\end{array}$ & 13,1 & 13,0 & 13,1 & 12,9 & 13,3 & 12,4 & 12,6 & 14,1 & 15,1 & 16,0 \\
\hline \begin{tabular}{l} 
Serviços \\
\hline
\end{tabular} & 0,9 & 1,0 & 1,4 & 1,9 & 2,3 & 2,5 & 2,8 & 2,4 & 2,7 & 2,6 \\
\hline
\end{tabular}

Fonte: Autor, baseado em Brasil (2011).

O mais preocupante, entretanto, é que no âmbito da graduação, os concluintes dos cursos das áreas das Ciências Sociais, Negócios e Direito, que possuem uma grande quantidade de cursos autorizados e reconhecidos, cresceram ainda mais no período avaliado - de 2000 a 2009 - e já representam mais de $40 \%$ de todos os concluintes. Por outro lado, concluintes de cursos de áreas consideradas estratégicas para o país e que apresentam grave carência de profissionais disponíveis como, por exemplo, as Engenharias, diminuíram de $7 \%$ para $5,9 \%$. Atualmente existe consenso no meio governamental acerca da importância fundamental de ampliar o número de engenheiros no país. $\mathrm{O}$ Brasil forma por ano cerca de 26 mil engenheiros, sendo que mais de $50 \% \mathrm{em}$ cursos de engenharia civil, área que emprega pouca tecnologia. Setores mais novos, como os da cadeia produtiva do petróleo e biocombustíveis, são os que mais carecem de novos profissionais. Em comparação, na China o número de 
engenheiros que entram no mundo do trabalho por ano chega a 450 mil, na Índia 200 mil e na Coréia do Sul 80 mil. O Brasil tinha apenas seis engenheiros para cada mil trabalhadores em 2009. Nos Estados Unidos e no Japão, essa proporção era de 25 para cada grupo de mil pessoas economicamente ativas (TELLES, 2009).

Tabela 3 - Porcentagem de concluintes de mestrado ou doutorado por áreas do conhecimento, 2000-2009

\begin{tabular}{l|r|r|r|r|r|r|r|r|r|c}
\hline \multicolumn{1}{c|}{ Ano } & $\mathbf{2 0 0 0}$ & $\mathbf{2 0 0 1}$ & $\mathbf{2 0 0 2}$ & $\mathbf{2 0 0 3}$ & $\mathbf{2 0 0 4}$ & $\mathbf{2 0 0 5}$ & $\mathbf{2 0 0 6}$ & $\mathbf{2 0 0 7}$ & $\mathbf{2 0 0 8}$ & $\mathbf{2 0 0 9}$ \\
\hline Ciências Agrárias & 10,7 & 10,9 & 10,0 & 10,1 & 10,0 & 10,0 & 10,1 & 9,9 & 10,4 & 10,5 \\
\hline $\begin{array}{l}\text { Ciências } \\
\text { Biológicas }\end{array}$ & 9,2 & 8,9 & 8,5 & 8,3 & 8,3 & 8,2 & 8,2 & 7,9 & 8,1 & 7,8 \\
\hline $\begin{array}{l}\text { Ciências Exatas e } \\
\text { da Terra }\end{array}$ & 10,6 & 10,5 & 9,6 & 9,3 & 9,1 & 8,9 & 8,5 & 8,6 & 8,5 & 8,6 \\
\hline $\begin{array}{l}\text { Ciências } \\
\text { Humanas }\end{array}$ & 16,6 & 17,2 & 17,3 & 16,4 & 16,6 & 16,8 & 16,9 & 17,1 & 17,3 & 17,2 \\
\hline $\begin{array}{l}\text { Ciênc. Sociais } \\
\text { Aplicadas }\end{array}$ & 13,6 & 14,6 & 16,1 & 16,5 & 15,2 & 14,4 & 15,0 & 14,3 & 14,1 & 13,6 \\
\hline $\begin{array}{l}\text { Ciências da } \\
\text { Saúde }\end{array}$ & 16,8 & 15,2 & 16,0 & 16,0 & 15,3 & 15,7 & 15,5 & 15,7 & 14,8 & 15,7 \\
\hline $\begin{array}{l}\text { Engenharias e } \\
\text { Informática }\end{array}$ & 14,2 & 13,3 & 12,9 & 13,5 & 14,9 & 14,6 & 13,9 & 13,2 & 12,7 & 12,5 \\
\hline $\begin{array}{l}\text { Linguística, } \\
\text { Letras e Artes }\end{array}$ & 5,7 & 6,2 & 6,0 & 5,7 & 6,2 & 6,1 & 6,3 & 6,8 & 6,6 & 6,5 \\
\hline \begin{tabular}{l} 
Multidisci-plinar \\
\hline
\end{tabular} & 2,7 & 3,1 & 3,6 & 4,3 & 4,5 & 5,3 & 5,6 & 6,5 & 7,6 & 7,7 \\
\hline
\end{tabular}

Fonte: Autor, baseado em Brasil (2011).

No ano de 2009, no âmbito dos cursos presenciais, Direito e Administraçáo possuíam, cada um, mais de $10 \%$ dos alunos matriculados e também dos concluintes de todo o sistema. Por outro lado, Engenharia elétrica, um dos cursos mais importante no momento atual de desenvolvimento do Brasil, representava aproximadamente $1 \%$ dos alunos matriculados e concluintes (INEP, 2012). Não há dúvida que tais diferenças de percentuais estão diretamente relacionadas à expansão das instituiçôes e dos cursos privados no sistema. A criação e manutenção de cursos de Direito e Administração tem custo reduzido em relaçãoo a cursos com maior demanda de tecnologia e laboratórios como, por exemplo, as Engenharias. A própria uniformidade dos critérios de avaliação utilizados pelo Inep induz as instituiçóes privadas a optarem por criarem cursos que demandam menos investimentos e que implicam em menores riscos de continuidade. Os instrumentos de avaliação praticamente não consideram as diferenças de 
demanda ou necessidade social das diferentes áreas do conhecimento. Logo, para uma instituição que trata a educação superior como um mero negócio, é muito mais rentável criar cursos que requerem baixos investimentos em infraestrutura e que, ao mesmo tempo, apresenta alta "demanda" pelo status social que possuem, como, por exemplo, um curso de Direito.

Além de nos últimos dez anos não ter ocorrido uma adequada diversificação dos concluintes dos cursos de graduação conforme as necessidades dos diferentes segmentos socioeconômicos, a parcela de graduados no conjunto da população economicamente ativa brasileira - $10 \%$ - ainda continua muito baixa se comparada, por exemplo, com a média dos países mais desenvolvidos da Organização para a Cooperação e Desenvolvimento Econômico (OCDE) - 28\% (BRASIL, 2011). Portanto, é evidente que além de ser insuficiente, a expansão privada dos últimos tempos tem gerado uma preocupante falta de alinhamento entre as demandas do mundo do trabalho para o desenvolvimento do país e o perfil em formação na educação superior brasileira.

\section{A iniquidade no acesso e na conclusão}

A ampliação do nível de equidade da educação superior se transformou num dos maiores desafios dos sistemas nacionais nesse início de século XXI. Tal condição pode ser constatada pelo destaque que importantes organismos multilaterais, como UNESCO, OCDE e Banco Mundial, têm deferido ao assunto. Recentes e importantes documentos e relatórios desses organismos sobre educação superior abordam a questão da iniquidade dos sistemas nacionais. O comunicado final da Conferência Mundial sobre Educação Superior da UNESCO de 2009, The new dynamics of higher education and research for societal change and development, observa que, apesar dos esforços dos últimos dez anos, grandes disparidades ainda persistem e constituem uma fonte maior de desigualdade nos sistemas de educação superior dos países (UNESCO, 2009a). O documento Tertiary Education for the Knowledge Society: pointers for policy development, da OCDE, publicado em 2008, também destaca a importância da implementaçáo de indicadores para monitorar e identificar o acesso, participação, retenção e sucesso de grupos ou minorias em desvantagem no âmbito da educação superior.

Nos últimos dez anos, no Brasil, apesar do avanço em alguns indicadores, não ocorreram mudanças significativas no nível de iniquidade regional e de acesso das minorias em nível de graduação no sistema de educação superior. A 
diferença de atendimento entre as grandes regióes do Brasil no período 2001 2009, por exemplo, teve redução discreta. Das cinco regiōes do país, apenas duas, Nordeste e Sul, apresentaram melhoras diferenciadas na relação entre o percentual de graduandos e o percentual da população. A região CentroOeste e a região Sudeste, essa última a mais populosa e mais rica, praticamente mantiveram iguais os níveis de atendimento no conjunto de todo o sistema. A regiâo Norte, justamente a menos desenvolvida do país, sofreu uma redução de 0,81 para 0,76 na relação entre o percentual de graduandos e o percentual da população (tabela 4). $\mathrm{O}$ ideal seria que todas as regióes tivessem a relaçấo com o valor um. Além disso, a adequação ocorrida na relação entre população e alunos matriculados da regiáo Nordeste, muito provavelmente decorre do recente e diferenciado crescimento da economia da região e não a um quadro de política pública de democratização do acesso.

Tabela 4 - Relaçáo entre o percentual de graduandos das regióes do país e o percentual da populaçáo dessas regióes, 2001-2009

\begin{tabular}{|c|c|c|c|c|c|c|c|c|c|c|}
\hline REGIÁO & & 2001 & 2002 & 2003 & 2004 & 2005 & 2006 & 2007 & 2008 & 2009 \\
\hline \multirow[t]{3}{*}{ Norte } & $\%$ grad. & 4,68 & 5,46 & 5,92 & 6,02 & 5,86 & 6,00 & 6,23 & 6,36 & 6,14 \\
\hline & $\%$ pop. & 5,75 & 5,88 & 6,03 & 7,87 & 7,93 & 7,98 & 8,02 & 8,07 & 8,11 \\
\hline & Relação & 0,81 & 0,93 & 0,98 & 0,76 & 0,74 & 0,75 & 0,78 & 0,79 & 0,76 \\
\hline \multirow[t]{3}{*}{ Nordeste } & $\%$ grad. & 15,19 & 15,59 & 16,09 & 16,33 & 16,58 & 17,02 & 17,48 & 17,97 & 18,87 \\
\hline & \% pop. & 28,71 & 28,70 & 28,68 & 28,14 & 28,15 & 28,15 & 28,16 & 28,16 & 28,17 \\
\hline & Relação & 0,53 & 0,54 & 0,56 & 0,58 & 0,59 & 0,60 & 0,62 & 0,64 & 0,67 \\
\hline \multirow[t]{3}{*}{ Sudeste } & $\%$ grad. & 51,69 & 50,18 & 49,34 & 49,36 & 49,62 & 49,90 & 49,83 & 49,46 & 49,19 \\
\hline & \% pop. & 43,42 & 43,30 & 43,17 & 42,28 & 42,20 & 42,13 & 42,07 & 42,01 & 41,95 \\
\hline & Relação & 1,19 & 1,16 & 1,14 & 1,17 & 1,18 & 1,18 & 1,18 & 1,18 & 1,17 \\
\hline \multirow[t]{3}{*}{ Sul } & $\%$ grad. & 19,85 & 19,47 & 19,17 & 19,05 & 18,98 & 18,28 & 17,71 & 17,46 & 16,93 \\
\hline & \% pop. & 15,04 & 14,99 & 14,94 & 14,62 & 14,59 & 14,56 & 14,53 & 14,51 & 14,48 \\
\hline & Relação & 1,32 & 1,30 & 1,28 & 1,30 & 1,30 & 1,26 & 1,22 & 1,20 & 1,17 \\
\hline Centro- & $\%$ grad. & 8,59 & 9,30 & 9,49 & 9,24 & 8,95 & 8,80 & 8,75 & 8,75 & 8,87 \\
\hline \multirow[t]{2}{*}{ Oeste } & \% pop. & 7,07 & 7,13 & 7,17 & 7,09 & 7,13 & 7,18 & 7,22 & 7,25 & 7,29 \\
\hline & Relação & 1,21 & 1,30 & 1,32 & 1,30 & 1,26 & 1,23 & 1,21 & 1,21 & 1,22 \\
\hline
\end{tabular}

Fonte: Autor, baseado em IBGE (2011) e Brasil (2011).

Da mesma forma, os indicadores de atendimento da educação superior às parcelas menos favorecidas da sociedade também tiveram melhorias discretas. No ano de 2001, a taxa de atendimento da populaçáo branca era de $14,1 \%$ e da populaçáo negra de 3,2\% - considerando pretos e pardos. Seis anos depois, 
em 2007, a taxa de atendimento da população negra melhorou em 3,7 pontos percentuais e da populaçáo branca em 5,7 pontos percentuais. Ou seja, apesar de no período 2001-2009 ter ocorrido um aumento percentual maior para a populaçáo negra, a vantagem percentual de atendimento pró-populaçáo branca aumentou de $10,9 \%$ para $12,9 \%$ (tabela 5 ).

Tabela 5 - Relaçáo entre taxas de atendimento de raças da populaçáa, 20012007

\begin{tabular}{|c|c|c|c|c|c|c|c|}
\hline Cor & 2001 & 2002 & 2003 & 2004 & 2005 & 2006 & 2007 \\
\hline Branca & 14,1 & 15,5 & 16,6 & 16,1 & 17,3 & 19,2 & 19,8 \\
\hline Negra & 3,2 & 3,8 & 4,4 & 4,9 & 5,5 & 6,3 & 6,9 \\
\hline Relaçáo & 4,4 & 4,1 & 3,8 & 3,3 & 3,1 & 3,0 & 2,9 \\
\hline
\end{tabular}

Fonte: Autor, baseado em IPEA (2011).

Assim, parece ficar claro que a expansão em curso não é suficiente para fazer frente ao alto nível de iniquidade do sistema da educação superior brasileiro. Além disso, equidade na educação superior não é apenas ampliação do acesso. A verdadeira equidade na educação superior implica em confrontar desigualdades sociais profundamente enraizadas na estrutura histórica, cultural e econômica que impactam significativamente na capacidade dos indivíduos competirem. Por exemplo, as distribuiçóes de riqueza e de recursos desiguais contribuem para a desvantagem de determinados grupos da população. A última Conferência Mundial sobre Educação Superior da UNESCO (2009a, p. 2) destaca que

[...] equidade não é simplesmente uma questão de acesso - o objetivo deve contemplar também toda a trajetória e a conclusão, tempo em que deve ser assegurado o bem estar do aluno. Este auxílio deve incluir suporte financeiro e educacional adequados para aqueles que vivem em comunidades pobres e/ou marginalizadas.

Assim, ao se desenvolver análises acerca da equidade da educação superior é preciso considerar não apenas o acesso dos grupos sociais menos favorecidos, mas também os resultados alcançados por esses grupos no transcorrer dos cursos e na obtenção de êxito na conclusão da graduação. Nessa perspectiva, o Exame Nacional de Desempenho de Estudantes (Enade), provavelmente a melhor fonte de informaçôes sobre os concluintes da graduação brasileira, com ótima amostragem de todo o sistema, demonstra a existência de "seletividade" na conclusão de cursos, principalmente, nos considerados de "elite". No Enade 
do ano de 2007, por exemplo, enquanto, em média, 73\% dos concluintes pertenciam a famílias com renda mensal de até três salários mínimos, no curso de medicina, apenas $26 \%$ pertenciam a esse grupo de baixa renda. No mesmo ano, no curso de Serviço Social, quase $90 \%$ dos concluintes pertenciam a famílias com renda mensal de até três salários mínimos. No mesmo sentido, enquanto, na média de todos os cursos, $60 \%$ dos concluintes tinham mães com formação de ensino médio ou superior, entre os concluintes do curso de Medicina, $92 \%$ das mães tinham formação equivalente (tabela 6). Em relação a outros aspectos de perfil social, enquanto quase $80 \%$ dos alunos de Medicina se autodenominavam de cor branca, apenas $1 \%$ se considerava de cor negra e, ao passo que, $44 \%$ dos alunos do Enade de 2007 e 29\% do Enade de 2008 cursaram o ensino médio em escolas privadas, $89 \%$ dos alunos da medicina realizaram seus estudos em escolas de igual categoria administrativa.

Tabela 6 - Porcentagem de concluintes em cursos por indicador social no ENADE 2007

\begin{tabular}{l|c|c|c}
\hline & Serviço Social & Medicina & Geral \\
\hline Renda mensal da família - até 3 sal. Mínimos & $90 \%$ & $26 \%$ & $73 \%$ \\
\hline $\begin{array}{l}\text { Escolaridade da máe - nível médio ou } \\
\text { superior }\end{array}$ & $41 \%$ & $92 \%$ & $60 \%$ \\
\hline Cor da pele branca & $59 \%$ & $79 \%$ & $68 \%$ \\
\hline Cor da pele negra & $10 \%$ & $1 \%$ & $6 \%$ \\
\hline
\end{tabular}

Fonte: Autor, baseado nos microdados do Enade em INEP (2012).

Outro aspecto que deve ser agregado na análise da equidade no sucesso dos concluintes é a categoria administrativa das instituiçóes e a presumível qualidade das mesmas. Na comparação com as instituiçóes privadas, as instituiçóes estatais federais são consideradas de excelência. No geral, as instituiçóes privadas (que possuem a maioria dos concluintes com, por exemplo, $77 \%$ dos alunos em 2009) apresentam desempenho inferior nas avaliações externas em relação às instituiçóes estatais 4 ou 5- em 2007, 35,5\% das estatais obtiveram os conceitos mais altos do Índice geral de Cursos (IGC) -, enquanto apenas 4,9\% das privadas obtiveram tais conceitos. Além disso, as instituições privadas, especialmente as não-universitárias, não desenvolvem as dimensões pesquisa e extensão, e o corpo docente é menos titulado do que nas instituições estatais - em 2009, as estatais federais tinham $50 \%$ do corpo docente com doutorado e as instituiçóes privadas com apenas 14\% (INEP, 2012). Em ambos os exames, de 2007 e 2008, a porcentagem de alunos concluintes provenientes do ensino médio de escolas 
privadas é sempre superior nas federais do que nas instituições privadas, ou seja, o ingresso e sucesso nas instituiçốes de educação superior consideradas de excelência (federais) tende a ser mais acessível aos egressos das escolas de ensino médio (privadas) frequentadas pelos alunos das classes mais abastadas.

Quando o perfil socioeconômico dos concluintes é analisado levando em conta os conceitos subjetivos de status social de curso e qualidade da categoria administrativa da instituição, o nível da iniquidade da educação superior brasileira se revela de forma inequívoca. Nos exames do Enade de 2007 e 2008, o perfil socioeconômico variou de forma significativa dos concluintes de cursos de instituiçóes privadas para os concluintes de cursos de profissóes com status social de instituiçôes federias (tabela 7). Por exemplo, no Enade de 2007, enquanto $67 \%$ dos concluintes de Medicina nas instituiçóes estatais federais pertenciam a famílias com renda superior a 10 salários mínimos mensais, quase $90 \%$ dos concluintes de Serviço Social nas instituições privadas pertenciam a famílias com menos de 10 salários mínimos. Tais números adquirem maior dimensão de injustiça na medida em que estudos indicam que no ano de 2009 cerca de $40 \%$ da população brasileira, mais de 70 milhões de pessoas, possuíam renda familiar inferior a R\$1.064,00 (FGV, 2010). No Enade de 2008, tal distorção se repete na comparação sociocultural entre Computação e Informática das federais e Pedagogia das privadas. Enquanto $80 \%$ dos concluintes dos concorridos cursos da área de informática nas federais tinham mães com formação em nível médio ou superior, aproximadamente $72 \%$ dos concluintes de Pedagogia nas privadas tinham mães com formação de, no máximo, ensino fundamental.

Tabela 7 - Concluintes de cursos em diferentes categorias administrativas no Enade de 2007 e 2008 por faixa de renda familiar

\begin{tabular}{c|cc|cc|cc|cc|cc}
\hline & \multicolumn{3}{|c|}{ Instituiçóes privadas } & \multicolumn{3}{c}{ Instituiçóes estatais federais } \\
\hline $\begin{array}{c}\text { Faixa de } \\
\text { renda } \\
\text { familiar } \\
\text { mensal - } \\
\text { sal. mínimo }\end{array}$ & $\begin{array}{c}\text { Pedagogia } \\
2008\end{array}$ & $\%$ & $\begin{array}{c}\text { Serviço } \\
\text { social } \\
2007\end{array}$ & $\%$ & $\begin{array}{c}\text { Eng. civil } \\
2008\end{array}$ & $\%$ & $\begin{array}{c}\text { Compu- } \\
\text { tação } \\
2008\end{array}$ & $\%$ & $\begin{array}{c}\text { Medicina } \\
2007\end{array}$ & \\
\hline Até 3 & 13817 & 54 & 1475 & 45 & 230 & 17 & 162 & 16 & 64 & 6 \\
\hline 3 a 10 & 9982 & 39 & 1411 & 43 & 601 & 45 & 488 & 48 & 303 & 28 \\
\hline $\mathbf{1 0}$ a 20 & 1296 & 5 & 301 & 9 & 301 & 23 & 241 & 24 & 386 & 36 \\
\hline 20 a 30 & 251 & 1 & 51 & 2 & 95 & 7 & 82 & 8 & 177 & 16 \\
\hline Mais de 30 & 119 & 0 & 14 & 0 & 96 & 7 & 46 & 5 & 146 & 14 \\
\hline Total & 25465 & & 3252 & & 1323 & & 1019 & 1076 & \\
\hline
\end{tabular}

Fonte: Autor, baseado nos microdados do Enade em INEP (2012). 
Com base nessas comparações, é plausível dizer que os alunos pobres estão mais propensos a "pagar" para concluir cursos com menor status social nas instituições de menor qualidade, enquanto, de forma absurdamente injusta, os alunos ricos tendem a ter acesso quase exclusivo e "gratuito" às graduações de maior retorno financeiro e social nas melhores instituições. Dessa forma, a análise do desempenho dos alunos concluintes dos exames de 2007 e 2008, nos diferentes estratos sociais, evidencia a existência de uma condicionante social importante para a conclusão da graduação, visto que o acesso a cursos considerados de "elite" é seletivo. Esta análise do perfil socioeconômico e cultural dos concluintes é, talvez, a maior prova de que a expansão da educação superior brasileira está sendo determinada pelo mercado visto que um Estado democrático atuante jamais permitiria uma situação com tal nível de iniquidade.

\section{Conclusão}

Da mesma forma que vem ocorrendo com outros setores estratégicos para o desenvolvimento socioeconômico dos países, a educação superior também está passando por um processo de mercantilização, com forte expansão da rede privada. De maneira geral, os argumentos e as justificativas para a ampliação da lógica de mercado na educação superior estão relacionados com os pressupostos liberais de que os parcos recursos públicos devem ser empenhados em áreas mais sensíveis e que a competição mercantil levaria a uma maior produtividade e eficiência dos sistemas, com consequente melhoria na qualidade e equidade no provimento dos serviços educacionais.

Por outro lado, a literatura sobre o fenômeno da mercantilizaçáo da educação superior, que demonstra que a educação vem sofrendo uma reorientação de acordo com os princípios dos mercados, destaca que o mercantil tem interesses de curto prazo, bem diferentes dos relativos a um projeto de naçáo, e que, portanto, a competição de mercado na educação superior inviabiliza o desenvolvimento dos sistemas no sentido do interesse maior das sociedades e dos países.

O presente trabalho contribuiu com a elucidação de tal contradição por meio da avaliação do grau de coerência da expansão preponderantemente privada da educaçấo superior brasileira com os interesses maiores da sociedade e do país. Com vistas a identificar quais os resultados de tal expansão, foram 
analisados dois importantes conceitos da avaliação de sistemas de educação superior: formação da força de trabalho e equidade do sistema.

Os estudos e acompanhamentos dos alunos graduandos nas diferentes áreas do conhecimento nos últimos anos demonstraram que a expansão privada tem gerado uma preocupante falta de alinhamento entre as demandas do mundo do trabalho e a formação em desenvolvimento na educação superior brasileira. Da mesma forma, a análise dos indicadores de atendimento nas diferentes regióes do país e de acesso para grupos minoritários demonstraram que a expansão privada não tem reduzido de forma significativa a iniquidade do sistema. A expansão da educação superior se dá "ao gosto" do mercado tanto pela preferência de novos cursos das áreas do conhecimento em que o custo de implantação é mais baixo como pela localização geográfica das novas instituiçóes onde o potencial de retorno financeiro das mensalidades é maior. Assim, avanços como interiorização mais significativa do sistema e ampliação da formação em áreas estratégicas não se efetivam.

O nível de iniquidade observado no perfil dos concluintes dos exames Enade, é outra evidência de que é o interesse do mercado, e não as políticas de Estado, quem está definindo os rumos da educação superior no Brasil. A análise do Enade permite observar que alunos concluintes pertencentes às camadas mais pobres têm presença preponderante em cursos sem status social nas instituições menos qualificadas que cobram mensalidades, enquanto alunos provenientes das classes socioeconômicas privilegiadas têm maior presença nos cursos de "elite" das melhores instituiçôes que, geralmente, são gratuitas.

Por conseguinte, o sistema de educação superior não consegue "quebrar a corrente" de desvantagem das classes menos favorecidas nos diferentes níveis e, por conseguinte, reproduz privilégios que a elite começa a ter ainda na educaçẫo infantil, passando pelo ensino fundamental e médio privado de reconhecida qualidade e, se consolidando, na "seletiva" graduação pública federal. O sistema educacional como um todo, possui uma iniquidade perversa e reproduz a desigualdade econômica e social existentes no país.

Portanto, é evidente que no Brasil a expansão da educação superior não está ocorrendo de acordo com um planejamento ou seguindo alguma orientação de política de Estado, mas sim na linha dos interesses das instituiçóes privadas, principalmente as com fins lucrativos. No contexto atual da educação superior brasileira, o Estado está sendo inoperante e o mercado está impondo sua lógica de forma determinante. 


\section{Notas}

${ }^{1}$ A taxa de escolarização líquida considera apenas os alunos matriculados com idade adequada ao nível de estudo em análise. Tal faixa etária para a educação superior é entre 18 e 24 anos. Assim, a taxa de escolarização líquida na educação superior é a proporção da quantidade de alunos com idade entre 18 e 24 anos matriculados em relação à população existente na faixa etária de 18 a 24 anos.

${ }^{2}$ A taxa de escolarizaçáo bruta considera todos os alunos matriculados, independente da idade. Portanto, tal taxa na educação superior é a proporção da quantidade de alunos matriculados em relação à população existente na faixa etária de 18 a 24 anos.

${ }^{3}$ Neste artigo, para efeito de especificação conceitual, entende-se o Estado como o conjunto de instituiçóes que acompanham e administram uma naçâo organizada política, social e juridicamente e que é dirigida por um governo que possuí soberania e capacidade de regular e intervir na sociedade civil e na economia.

${ }^{4}$ Neste artigo, para efeito de especificação conceitual, entende-se o mercado como o espaço no qual os agentes econômicos, tais como um indivíduo, uma família, uma empresa, um banco ou um país, procedem à troca livre de bens ou serviços, comparáveis entre si, com base num valor.

${ }^{5}$ Não obstante a natureza pública não estatal das instituiçôes comunitárias e confessionais sem fins lucrativos, bem como as características dessas instituiçôes de valores acadêmicos, de pesquisa e de compromisso social (raramente observadas em faculdades mercantis e nos grandes grupos educacionais corporativos com fins lucrativos), este artigo considera os números e alunos matriculados nas instituiçóes comunitárias e confessionais como pertencentes ao grupo de instituiçóes particulares visto que tais instituiçóes se sustentam por meio de mensalidades pagas pelos alunos e, por conseguinte, são diretamente impactadas em suas estratégias e práticas de provimento de ensino pela competição de mercado instaurada pela expansão das instituiçôes privadas com fins lucrativos. 


\section{REFERÊNCIAS}

BERTOLIN, Julio C. G. Avaliação da Qualidade do Sistema de Educação Superior Brasileiro em Tempos de Mercantilização: período 1994-2003. 2007. Tese (Doutorado em Educação) - Programa de Pós-Graduação em Educação, Faculdade de Educação, Universidade Federal do Rio Grande do Sul, Porto Alegre, 2007.

BRASIL. Ministério da Ciência, Tecnologia e Inovação. Indicadores Nacionais de Ciência, Tecnologia e Educação. Brasília: MCTI, 2011. Disponível em: $<$ http://www.mct.gov.br/index.php/content/view/740.htmlexecview=>. Acesso em: 16 ago. 2011.

CORREIA, Fernanda et. al. Diversificação e diversidade dos sistemas de ensino superior: o caso Português. Matozinhos, PT: Cipes, 2000.

DIAS SOBRINHO, José. Avaliação: políticas educacionais e reformas da educação superior. São Paulo: Cortez, 2003.

FGV. Fundação Getúlio Vargas. A nova classe média: o lado brilhante dos pobres. Rio de Janeiro: FGV/CPS, 2010.

HADDAD, Sérgio; GRACIANO, Mariângela. Educação: direito universal ou mercado em expansão. São Paulo em Perspectiva, São Paulo, v. 18, n. 3, p. 67-77, jul./set. 2004.

IBGE. Instituto Brasileiro de Geografia e Estatística. Brasília, 2011. Disponível em: <http://seriesestatisticas.ibge.gov.br/Default.aspx >. Acesso em: 16 ago. 2011.

INEP. Instituto Nacional de Estudos e Pesquisas Educacionais Anísio Teixeira. Brasília, 2012. Disponível em: <http://www.inep.gov.br>. Acesso em: 10 abr. 2012.

IPEA. Instituto de Pesquisa Econômica Aplicada. Brasília, 2011. Disponível em: <http://www.ipeadata.gov.br/Default.aspx>. Acesso em: 17 ago. 2011.

JOHNSTONE, D. Bruce. The financing and management of higher education: a status report on worldwide reforms. Washington, DC: The World Bank, 1998. 
OECD. Organization Economic Co-operation and Development. Tertiary education for the knowledge society: pointers for policy development. Paris: OCDE, 2008.

SANTOS, Boaventura de Sousa. A Universidade no século XXI: para um reforma democrática e emancipatória da universidade. São Paulo: Cortez, 2004.

TEIXEIRA, Pedro et al. Markets in higher education: rhetoric or reality? Netherlands: Kluwer Academic Publishers, 2004.

TELLES, Márcia. Brasil sofre com a falta de engenheiros. Revista Inovação em Pauta, Brasília, n. 6, p. 11-15, 2009.

UNESCO. United Nations Educational, Scientific and Cultural Organization. World declaration on higher education for the twenty-first century: vision and action. Paris: UNESCO, 1998.

UNESCO. United Nations Educational, Scientific and Cultural Organization. Towards knowledge societies. Paris: UNESCO, 2005.

UNESCO. United Nations Educational, Scientific and Cultural Organization. The new dynamics of higher education and research for societal change and development: World Conference on Higher Education. Paris: UNESCO, 2009a.

UNESCO. United Nations Educational, Scientific and Cultural Organization. Trends in global higher education: tracking an academic revolution. Paris: UNESCO, 2009b.

WORLD BANK. Data Indicatores. Disponível em: <http://data.worldbank. org/indicator/SE.TER.ENRR>. Acesso em: 27 dez. 2011. 


\section{El (des)gobierno de expansión de la educación superior en Brasil: desde inoperancia del Estado a supremacía de la lógica del mercado}

\section{Resumen}

La educación superior brasileña ha experimentado en las dos últimas décadas un proceso de expansión. Desde mediados de la década de 1990 el sistema comenzó a mostrar un fuerte crecimiento, especialmente a través de la acreditación de nuevas instituciones privadas no universitarias. Este proceso dio lugar a un aumento significativo en los indicadores cuantitativos, como las tasas de asistencia, el número de cursos de grado y el número de alumnos matriculados. Sin embargo, es necesario investigar el nivel de alineación de esta expansión con las políticas de desarrollo socioeconómico y con los intereses de la sociedad (o del mercado). Este artículo realiza una revisión de la literatura sobre el fenómeno de la mercantilización de la educación superior, presenta y analiza los aspectos e indicadores de la expansión del sistema $\mathrm{y}$, finalmente, demuestra que los intereses privados son determinantes en el desarrollo de la educación superior brasileña.

Palabras claves: Educación superior. Expansión de la Educación Superior. Mercantilización de la educación

\section{Julio Cesar Godoy Bertolin}

E-mail: julio@upf.br
The (mis)government in expansion of Brazilian Higher Education: the inoperative of the state to the supremacy of market logic

\begin{abstract}
The Brazilian higher education has experienced a process of significant expansion in the last two decades From the mid-1990s the system began to show strong growth, especially through qualification of new nonuniversity private institutions. This process resulted in a significant increase in quantitative indicators, such as attendance rates, number of undergraduate courses and number of students enrolled. However, the level of alignment of this expansion with the policies of socioeconomic development and with the best interests of society (or market) need to be investigated. This article provides a review of literature on the marketization phenomenon of the higher education, it presents and analyzes aspects and indicators of system expansion and finally demonstrates that private interests are determinants in the development of Brazilian higher education.
\end{abstract}

Keywords: Higher education. Expansion of higher education. Marketization of education. 